\title{
Health system in Bangladesh: Challenges and opportunities
}

\author{
Anwar Islam ${ }^{1, ~ *, ~ T u h i n ~ B i s w a s ~}{ }^{2}$ \\ ${ }^{1}$ Adjunct Scientist and Consultant, Centre for Control of Chronic Diseases (CCCD), International Centre for Diarrheal Disease Research, \\ Bangladesh (ICDDR,B), Dhaka, Bangladesh; and Adjunct Professor, School of Health Policy and Management, York University, Toronto, \\ Canada \\ ${ }^{2}$ Research Officer, Centre for Control of Chronic Diseases (CCCD), International Centre for Diarrheal Disease Research, Bangladesh \\ (ICDDR,B), Dhaka, Bangladesh
}

\section{Email address:}

anwarhill@yahoo.com (A. Islam), aislam@yorku.ca (A. Islam), anwar.islam@icddrb.org (A. Islam)

\section{To cite this article:}

Anwar Islam, Tuhin Biswas. Health System in Bangladesh: Challenges and Opportunities. American Journal of Health Research. Vol. 2, No. 6, 2014, pp. 366-374. doi: 10.11648/j.ajhr.20140206.18

\begin{abstract}
The health system of Bangladesh relies heavily on the government or the public sector for financing and setting overall policies and service delivery mechanisms. Although the health system is faced with many intractable challenges, it seems to receive little priority in terms of national resource allocation. According to the World Health Organization (WHO 2010) only about 3\% of the Gross Domestic Product (GDP) is spent on health services. However, government expenditure on health is only about $34 \%$ of the total health expenditure (THE), the rest (66\%) being out-of-pocket (OOP) expenses. Inequity, therefore, is a serious problem affecting the health care system. Based on a review of secondary data, the paper assesses the current challenges and opportunities of the health system in Bangladesh. The findings suggest that although the health system faces multifaceted challenges such as lack of public health facilities, scarcity of skilled workforce, inadequate financial resource allocation and political instability; Bangladesh has demonstrated much progress in achieving the health-related Millennium Development Goals (MDGs) especially MDG 4 and MDG 5. Although the country has a growing private sector primarily providing tertiary level health care services, Bangladesh still does not have a comprehensive health policy to strengthen the entire health system. Clearly, the most crucial challenge is the absence of a dynamic and proactive stewardship able to design and enforce policies to further strengthen and enhance the overall health system. Such strong leadership could bring about meaningful and effective health system reform, which will work more efficiently for the betterment of the health of the people of Bangladesh, and would be built upon the values of equity and accountability.
\end{abstract}

Keywords: Health System, Determinants of Health, Societal Response

\section{Introduction}

The health system is the societal response to the determinants of health. Every society believes in a set of determinants of health, not always following science or logic. The fundamental premise of a health system is the value of human life. The value that a society puts on human life largely determines the resources - human, material and financial - that it allocates for the health system. The effectiveness of a health system depends on the availability and accessibility of services in a form which the people are able to understand, accept and utilize. The Government of Bangladesh is constitutionally committed to "supply the basic medical requirements to all segments of the people in the society" and the "improvement of the nutritional and the public health status of the people" [1]. In its early phase, the health system in Bangladesh was primarily focused on providing curative services targeting maternal, child and newborn health. Since the 1990 s, with the development of modern science and technology and with the greater role of United Nations agencies and non-government organizations, the health systems gradually shifted its emphasis equally on health promotion and preventative services. The health services also expanded its reach. Yet a large number of the people of Bangladesh, particularly in rural areas, remain with little access to health care facilities. Nevertheless, it must be 
recognized that Bangladesh has a well-structured health system with three tiers of primary health care - Upazila Health Complexes (UHC) at the sub-district level, Union Health and Family Welfare Centres (UHFWC) at the Union (collection of few villages) level, and Community Clinics (CC) at the village level. These are backed by the District Hospitals providing secondary level care and the tertiary hospitals of various kind in large urban centres. From a purely structural point of view, the health system is based on sound principles covering the entire spectrum of services and care - from health education and promotion to treatment, care and rehabilitation. Moreover, the system is decentralized covering all districts, sub-districts and rural towns and villages in the country. The Government, thereby, seeks to create conditions whereby the people of Bangladesh have the opportunity to reach and maintain the highest attainable level of health. In short, Bangladesh has a good infrastructure for delivering primary health care services. However, due to inadequate logistics the full potential of this infrastructure has never been realized. Clearly the health system in Bangladesh needs further strengthening in order to fully realize its potential. A good health system improves and sustains people's lives tangibly every day. Health systems strengthening (HSS) is crucial for the successful scale up of disease control interventions as well as promoting health education [2-4]. Additional evidence also suggests that weak health systems are one of the main barriers in reaching the health-related Millennium Development Goals (MDGs)[4-5]. After independence Bangladesh has made tremendous progress in health and development. In some cases, it has made more impressive gains compared to most of its neighbors in reducing poverty, malnutrition, illiteracy and disease and deprivation. Despite these successes, the Bangladesh health system continues to suffer from innumerable challenges [6]. It is difficult to list and comment on all these challenges. This paper is concentrated on an analysis of a number of major challenges faced by the health system in Bangladesh.

\section{Methodology}

The paper is based on an extensive review of published and unpublished data/ information on health system in Bangladesh. These include relevant annual as well as special reports by the World Health Organization (WHO), the United Nations Children's Fund (UNICEF), United Nations Fund for Population Activities (UNFPA), the World Bank (2012), Bangladesh Bureau of Statistics (2009, 2011), and the Bangladesh Health Watch $(2007,2011)$-Reports by the Directorate General of Health Services as well as that of other national and international agencies were also considered. Articles and research papers published in scientific journals were also reviewed. In short, the paper is a review article based on secondary data. However the paper is exclusively based on reviews of English language articles and reports.

\section{Country Context}

Bangladesh is a poor and densely populated South Asian country. In 2013, it had a population of 156.6 million that is expected to increase to around 218 million by 2030 [7]. The country is undergoing considerable social and economic changes. Key demographic, economic and health indicators are summarized in Table 1. The country is experiencing a high rate of urbanization. The population of the capital city of Dhaka, for example, grew from 5.8 million in 1990 to 10.2 million by 2000 and is expected to increase to 16.8 million by 2015 [8]. The growing population in urban areas is often under-served in basic necessities like housing, security and access to essential services, including health, sanitation and potable water. Despite such rapid urbanization, Bangladesh is still primarily a rural country, with more than 70 per cent of the population currently living in rural areas [8]. Nearly half of the population-lives on less than US\$1.25 per day [9]. The population is relatively young, only 4 per cent being over 65 years of age or older. However, this is expected to change, with the proportion over 65 years of age or older rising to 6.6 per cent by 2025 [10]. Although there has been significant improvement in many health indicators in recent years, the

Table 1. Major selected Socio-demographic indicators of Bangladesh

\begin{tabular}{lll}
\hline Subject & Indicators & Value \\
\hline \multirow{4}{*}{ Population } & Total Population in million [18] & 156.6 \\
& Density (population/km2) [19] & 1015 \\
& Crude death rate per 1000 population [19] & 6 \\
Life & Male [19] & 66.6 \\
expectancy & Female [19] & 68.8 \\
(years) & Persons per hospital bed [19] & 1860 \\
& No. of doctors per 10,000 population [19] & 7.7 \\
Economic & GNI per capita-US\$ [20] & $\$ 640$ \\
indicators & PPP GNI per capita-US\$ [21] & $\$ 1620$ \\
& Annual growth rate (percent) [22] & 6.3 \\
Health & Sub-district hospitals [23] & 413 \\
Facilities/ & Secondary \& tertiary hospitals [23] & 117 \\
Hospitals & Medical Colleges [23] & 17 \\
& Infectious Disease Control Centres [23] & 5 \\
& Chest Hospitals [23] & 12 \\
Community Clinics [23] & 10,723 \\
Health & Physicians [24] & 11,300 \\
Workforce in & Nurses [24] & 13483 \\
public & Medical technologists [24] & 4,658 \\
facilities & Medical assistants [24] & 3,694 \\
& Domiciliary staff [24] & 23,285 \\
Health & Non-medical [24] & 218 \\
services & Persons per hospital bed [25] & 1,860 \\
& No. of doctors per 10,000 population [26] & 7.7 \\
Health & GDP spent on healthcare [1] & $3 \%$ \\
Financing & Health expenditure as a \% government & 7.4 \\
& budget [24] & $65.9 \%$ \\
& Out-of-pocket expenditure for health [24] & 23 \\
& Per capita total expenditure on health & \\
& (U.S.\$) [24] & \\
& Per cent coming from development & \\
& aid/partners [24] & \\
\hline
\end{tabular}

Sources: (18) World Bank 2013, (19) Bangladesh Bureau of Statistics 2011, (20) Trading Economics 2012a, (21) World Bank 2012a, (22) World Bank 2011c, (23) Bangladesh Health watch Report 2011 (24) Director General of Health Service 2010 (25) World Bank 2012 (26) Bangladesh Health Watch 2007 
government faces major issues concerning its capacity to plan and implement a broad range of health and population services [11]. A substantial proportion of the people, especially the poor, experience a wide range of health problems linked to socio-economic disparities [12-14]. Bangladesh has low per capita health expenditure as well as a low percentage of GDP spent on health. In 2009-10, the per capita national income and GDP were US\$750 and US\$684 respectively [15]. It is estimated that public sector health care financing accounts for only 34 percent of the total health care expenditure, which is inadequate to meet the demands of the population [16]. While table-1 indicates that the overall proportion of development assistance going to the health sector is approximately 8 percent [17], the WHO country-bycountry comparisons of health development assistance estimates that "nearly 16 percent of all health expenditures in Bangladesh are funded by international aid agencies". Regardless of the exact level, it does indicate the importance of the contribution of development partners in setting national health care priorities.

\subsection{Reforms of the Health Sector in Bangladesh}

In the early years following independence in 1971, the health system in Bangladesh was focused primarily on the requirements of rural areas. The First Five Year Plan (197378) highlighted the importance of building a network of health facilities - a hospital in every district, in some cases supplemented by a Maternal and Child Welfare Centre (MCWC), and an Upazila Health Complex (UHC) in every Upazila throughout the country. A number of vertical programs like malaria and small pox eradication programs were initiated in 1976. After the formulation of the First Five Year Plan (1973-78), the Government of Bangladesh (GOB) revived the family planning program in an organized manner and a separate Directorate of Family Planning was established within the Ministry of Health and Family Welfare. In 1975, an international consortium of bilateral development agencies, in coordination with the World Bank, started to provide financial and technical assistance to the GOB for the implementation of successive population and family planning projects, each five to six years in duration. The initial project, called the First Population Project (1975-80), provided support for re-establishing a physical infrastructure for family planning service delivery, which had been greatly damaged during the liberation war of 1971. The Second Population and Family Health Project (1980-86) provided funds for the further development of the national family planning program. The Third Population and Family Welfare Project (1986-92) began to provide some support for the reduction of infant mortality along with support for family planning services. The Fourth Population and Health Project (1992-98) provided further support for Maternal and Child Health and disease control activities along with family planning services. Primary Health Care (PHC) as the key ingredient of overall of health care was developed in the Second Five Year Plan of the country (1980-1985). However, at that point Bangladesh neither had a comprehensive national health policy nor a separate health sector plan outlining medium and long term goals. Five Year plans were used to set medium and long term objectives for all the sectors, including that of the health and family welfare sector.

A comprehensive review of the Fourth Population and Health Project led to concerns about the lack of progress in reducing maternal mortality and morbidity, the low utilization of Government health services, their costeffectiveness, as well as the sustainability and quality of such services. This review and its findings led to the further broadening of the public sector services and the formulation of the Health and Population Sector Program (HPSP). Under HPSP (1998-2003), measures had been taken to restructure the entire health system to make it more responsive to the health needs of the population. The goal of the program was to improve the health and family welfare status among the most vulnerable segments of the population - women, children and the poor through a client centered approach geared towards greater utilization of health, population and family welfare services. As a consequence, resources were allocated to those facilities and services (Upazila and below level facilities) that were most needed and used by the vulnerable groups Since 2009 the newly elected government undertook a massive effort to establish Community Clinics at the village level (1 Community Clinic for every 6,000 population) with a view to bring services to the doorsteps of the people at large. At the same time, since the second half of the 1990s, issues such as pro-poor focus, community participation and empowerment, accountability, publicprivate partnership for service delivery and demand-side financing gained momentum. Consequently, the structure and the service delivery model of the publicly-funded health system underwent profound changes.

Table 2. Achievements of the Bangladesh health system

\begin{tabular}{ll}
\hline Infant mortality rate (IMR) & 43 deaths per 1,000 live births \\
Child mortality rate & 11 deaths per 1,000 children \\
Under-5 mortality & 44 deaths per 1,000 live births. \\
Vaccination Coverage & $87.5 \%$ \\
Under age 5 are stunted & $41 \%$ \\
Severely stunted & $15 \%$ \\
Overall wasting & $16 \%$ \\
Children under age 5 are underweight & $36 \%$ \\
Severely underweight & $10 \%$ \\
Skilled attendance at deliveries & $32 \%$ \\
Maternal Mortality rate (MMR ) & 194 per 100,000 live birth \\
Antenatal Care Coverage (1 visits) & $67.70 \%$ \\
from any Provider & \\
Antenatal Care Coverage (4 visits) & $25.50 \%$ \\
from any Provider & $2.30 \%$ \\
Total fertility rate & \\
\hline
\end{tabular}

Source: Simple Vital Registration System (SVRS) 2011.

\subsection{Achievements of the Bangladesh Health System}

These restructuring efforts led to much improvement in the overall health and social development as reflected in some of the key socio-economic and demographic indicators (Table- 
2). It can be proudly said that Bangladesh has surpassed many neighboring countries in South Asia as well as so many other developing countries in terms of progress in achieving the health-related Millennium Development Goals (MDGs) as well as in improving the overall health status of its people. Over the last four decades, the average life expectancy of Bangladeshis increased from 44 years to 66 year today. Moreover, the gender disparity in average life expectancy that it had in the 1970s (females had a considerably lower average life expectancy than males) slowly disappeared as women's health status improved. Bangladesh has already met the MDG target of reducing under-five mortality rate. Data provided by the Sample Vital Registration System (SVRS) 2011 show that the under-five mortality rate was 44 per 1,000 live births in 2011 as compared to 146 in 1991. The MDG target of reducing the infant mortality rate is also on track.

According to the country's first MDG Progress Report, the maternal mortality ratio in 1990 was 574 per 100,000 live births. However, according to Bangladesh Maternal Mortality Survey (BMMS), maternal mortality declined from 322 in 2001 to 194 in 2010, a 40 percent decline in nine years. The average rate of decline from the base year has been about 3.3 percent per year, compared with the average annual rate of reduction of 3.0 percent required for achieving the MDG by 2015. The proportion of deliveries by medically trained providers has doubled from about 16 percent in 2004 to about 32 percent in 2011, mostly due to improvement in institutional delivery mechanism. Much of these improvements may be attributed to the country's tremendous success in achieving almost universal immunization coverage. While less than $5 \%$ of children were immunized at the time of independence, currently almost $100 \%$ of Bangladeshi children receive immunization thanks to the success of the Extended Program of Immunization (EPI) that penetrated the entire country. Bangladesh was successful in taming many communicable diseases too. Table 2 presents some of these successes of the Bangladesh health system.

\subsection{Challenge for the Health System in Bangladesh}

Despite these successes, the Bangladesh health system continues to suffer from many drawbacks Some of the major drawbacks of the health system include

\subsection{Limited Public Facilities}

A total of 536 public hospitals with 37,387 beds provide inpatient care services in Bangladesh for a population of 160 million. There are 413 Upazila (sub-district) Health Complexes which have limited inpatient care services (Table 2). Most UHCs has 20 beds primarily to cater to emergency needs of pregnant women. District hospitals are usually termed secondary care hospitals since unlike the medical college hospitals these have fewer specialty care facilities. Apart from these, there are different types of special care centres such as, infectious disease hospitals, tuberculosis hospitals, and leprosy hospitals which fall under secondary care health facilities. The medical college hospitals are located in the regional urban hubs covering several districts, and provide specialty care in a wide range of disciplines. These hospitals provide tertiary care services. Tertiary hospitals also include national level super specialty hospitals or centres which provide high end medical care services, specialized in only one particular area of healthcare. Over the last few decades, Bangladesh has experienced a rapid expansion of the secondary and tertiary care networks all over the country (Table 2). Of 64 districts, 59 have a hospital with secondary level health care. However, these hospitals have limited specialists, diagnostic and laboratory services. In addition, there are nine general hospitals with 100-250 bed capacity each. The types, number and size (bed counts) of public sector hospitals and their service packages are presented in Table-3. When compared with other developing countries, it becomes clear that Bangladesh does not have adequate number of hospital beds to serve its large population [9]. For example, while Bangladesh has only 0.4 bed per 1,000 population, Ghana has 0.9 bed per 1,000 population. Similarly Kenya at the same level of economic development as Bangladesh has 35 percent higher number of hospital beds than Bangladesh.

\subsection{Compromised Access}

A wide variety of inpatient care services is available in public hospitals. On the other hand, the three tiered PHC system (sub-district, union and village level) established to serve the population at large. However, access to this network of health care facilities is often seriously compromised. It should be noted that while basic health care service is supposed to be free in public hospitals and other facilities, patients end up bearing the costs of medicine and laboratory tests, as well as some additional unseen costs. These costs seriously restrict the access of the poor and the disadvantaged to most publicly-funded health care services. Moreover, in many public hospitals the available ambulances are either inoperative or being used by the physicians and other staff. Patients are deprived of use of ambulance services. In short, there is a gap between principle and practice in public health facilities seriously compromising the accessibility of the poor. The fact that almost $66 \%$ of health care costs are out-of-pocket expenses borne by individuals and families also serious restricts the access of the poor to the health system undermining the principle of equity so enshrined in the country's constitution.

\subsection{Lack of Essential Commodities}

Availability of drugs, medical supplies and family planning commodities is almost a constant problem in many public health facilities throughout the length and breadth of Bangladesh. While part of the problem lies with lack of effective supply chain management, lack of funds (or timely release of available funds) to pay for supplies is also a serious problem. Shortage of logistics in most public health care centers, especially at the Uazila Health Complexes and 
district hospitals is a common phenomenon. It is widely known that almost $65 \%$ of the ambulances in these facilities are non-functional at any point of time either because of lack of maintenance or fuel money. In many public health facilities $\mathrm{x}$-ray machines to incubators to various lab equipment are in need of either urgent repair or of replacement. Often essential drugs and family planning commodities meant for free distribution to patients and users are pilfered and sold to the private sector vendors.

\subsection{Unavailability of Health Workforce}

Unlike many service sectors, inpatient healthcare demands highly qualified labor force (health workforce) including physicians, dentists, nurses, midwives and medical technologists. Bangladesh has a chronic shortage of appropriately trained human resources of health including physicians, nurses and midwives. Such a shortage must be considered to be a strong limiting factor for population health [27]. Bangladesh government has sanctioned 20,234 positions for physicians of which 11,300 are currently filled up, which means a total vacancy of $44.2 \%$. In total 13,483 nurses are currently working in the public health facilities, while the total number of positions sanctioned are 17,183 . The distribution of vacant positions of different levels of nurses shows that around 96 percent positions of senior nurse are vacant. Corresponding vacancies for junior (class II) and aide nurse (class III) are 67.6 and 19.5 percent respectively. It means that vacant positions are higher among the nurses with higher qualifications. Table 3 presents information on sanctioned and vacant positions in public hospitals of different types of medical personnel. The highest vacancy of medical staff is observed in Barisal $(64.9 \%)$, followed by Khulna (58.2\%), Rajshahi (55.3\%), Sylhet (54.7\%), Chittagong (50.7\%) and Dhaka (25.4\%) [28]. In other words, there is almost a direct relationship between distance from the capital Dhaka and the number of vacant health personnel positions - the greater the distance the greater the percentage of vacant positions. These shortages are clearly undermining the quality of the health care system.

Table 3. Shortage of Health service providers in public facilities in Bangladesh.

\begin{tabular}{lll}
\hline Types of medical care and staff & Sanctioned & Vacant \\
\hline Allopathic Medicine & & \\
Physicians & 20,234 & 8,934 \\
Senior nurse & 161 & 155 \\
Junior nurse & 463 & 313 \\
Aide nurse & 16,559 & 3,232 \\
Medical technologists & 6,150 & 1,492 \\
Medical assistants & 5,411 & 1,717 \\
Domiciliary staff & 26,416 & 3,131 \\
Non-medical & 466 & 248 \\
Alternative medicine & & \\
Unani & 66 & 46 \\
Ayurvedic & 66 & 44 \\
Homeopathic & 66 & 50 \\
Compounders & 64 & 16 \\
Herbal garden assistants & 467 & 42 \\
\hline
\end{tabular}

Source: Directorate General of Health Services(DGHS), 2010.

\subsection{Lack of Devolution}

Although decentralized, the health system never went through a process of devolution. In other words, power and decision-making remain concentrated in the MHFW in Dhaka with the UHCs simply carrying out plans and programs decided by the Ministry. Plans and programs, therefore, often do not reflect local realities. Moreover, lack of decision-making power at the local level often prevents the local health professionals from effectively responding to unique local level emergencies or crisis.

\subsection{Lack of Local Level Planning}

It flows from the earlier one - lack of devolution. It seems that Upazila Health and Family Planning officials are always asked to develop a plan of action to be implemented during the coming year based on local epidemiological and demographic situation. Although these local area plans are routinely submitted to the Ministry, they seldom receive any attention while developing overall health sector plans. It is apparent that they remain largely an exercise in futility.

\subsection{Misuse or Misappropriation of Resources}

It is a common complaint from clients that medicines or drugs that are supposed to be available free of charge (or with minimal fee) often "disappear" from the UHCs and find their way to the local market to be sold at a hefty price. X-ray films remain routinely unavailable at the UHC forcing a patient in need of one to buy it from the local market. It is reported that because of either misuse or inappropriate use almost $65 \%$ of the ambulances given to the Upazila Health Complexes are "inoperable" or non-functional at any given point of time [29]. Clearly the patients suffer for the inefficiency of the health system.

\subsection{Lack of Community Empowerment at the Local Level}

Because of government regulations, community management committees are often established at the Upazila level to oversee the UHCs. However, these committees seldom truly represent their communities or are empowered to demand accountability from the health officials. Devoid of meaningful community participation in the planning and provision of health care services at the local level, the UHCs continue to be dominated by the bureaucrats. Bureaucratic efforts in forming local committees hardly recognize that community is a heterogeneous entity and that men, women, rich and poor, Muslims and non-Muslims, all are needed to represent a community. A committee formed of so-called community leaders (often representing the rich and the powerful) does not necessarily represent a community in the real sense of the term. Bangladesh health system at the local level fails to understand this reality while talking about community participation. 


\subsection{Lack of Public Health and Management Expertise at the District and Upazila Levels}

Civil surgeons are responsible to oversee the district health system while Upazila Health and Family Planning Officers (UHFPOs) are the heads of the Upazila Health Complexes. Civil surgeons are physicians and so are most of the UHFPOs. In many cases these physicians have very little knowledge or expertise on public health or in management. Although they are good physicians, they often lack expertise in management. Consequently, the health system at the district and sub-district levels suffers from paucity of knowledge on public health and of management expertise. More catastrophic is the almost total absence of ethics guiding the behavior of health professionals. Although the government has prescribed office hours for all employees at the district hospitals, UHCs and community clinics, physicians in these health care institutions often have their own "office hours" quite different from that of the official one. Inconvenience to the patients seldom gets any attention. Patients are often neglected or even abused by the health care workers; their dignity and privacy seldom respected. Ethics and morality have disappeared so much that patients are often diverted or enticed to private clinics or to a physician's home so that he/she can be charged a fee. A "normal" delivery could be delayed beyond the office hours so that a fee can be exacted. Or a "normal" delivery could be transformed into a "cesarean" one to earn some extra bucks. Morality and ethics that used to guide physicians and other health care professionals seem to have disappeared from Bangladesh. Hippocratic Oath that guided physician-patient relationships for centuries does no longer get covered in Bangladesh's medical education.

\subsection{Inadequate Financial Resources}

In Bangladesh, about $3.4 \%$ of GDP is spent on health, out of which the government contribution is about $1.1 \%$. In term of dollar, the total health expenditure in the country is about US\$ 12 per capita per annum, of which the public health expenditure is only around US\$ 4 only. More than two-thirds of the total expenditure on health is privately financed, through out-of-pocket payments. Of the remaining one-third (public financing), about $60 \%$ is financed by the Government out of tax revenues, development outlays, and the remaining $40 \%$ through international development assistance. Health care expenditure of the MOHFW at different levels shows that $27 \%$ of the primary level health care allocation is going to the richest quintile and $21 \%$ to the poorest quintile.

Health financing is mainly tax-based, along with the financing from development partners. But the poorer people spend more on health through out-of-pocket payment, which often leads to their impoverishment. Health insurance is almost non-existent in Bangladesh. Although some NGOs have piloted health insurance schemes in recent years, it will presumably take a longer period of time to gain wider public acceptance.

\subsection{Growing and Continuing Inequity within the Health System}

Poor and the disadvantaged groups still have significantly less access to health care services than the rich and the privileged. For example, only $8 \%$ of pregnant women from the poorest income quintile deliver their babies at any health centre or clinic compared to $53 \%$ pregnant women from the richest income quintile. There is serious disparity in terms of antenatal and post-natal care too. While only $31 \%$ pregnant women from the poorest income quintile ever seek antenatal care, the rate is as high as $82 \%$ among the richest income quintile. The corresponding figures for post-natal care are $7 \%$ and $51 \%$ for the poorest and richest income quintile mothers respectively. Most importantly, poor continues to die at a younger age than their rich compatriots. The infant mortality rate varies from a low of 43 per 1,000 live births among the richest income quintile to over 85 per 1,000 live births among the poorest income quintile [30] The MOHFW could hardly take any effective measures over the years to carefully assess the social determinants of such inequities and to come up with effective corrective measures. The problems faced by the health system are well known and yet the leadership at the top seldom demonstrates the eagerness and/or the ability to tackle them. A health system consists of six interrelated and interdependent building blocks - efficient and effective health service delivery; appropriately skilled, adequate number and properly distributed health workforce; a wellfunctioning health information system; equitable access to essential medical products and technologies; adequate financing; and leadership and good governance. It is doubtful whether the steward of the Bangladesh health system truly appreciates and comprehends the inter-relatedness of all these building blocks and the need to addressing them simultaneously in order to overcome the drawbacks of the overall health system. The steward must realize that without such a comprehensive approach it would be futile to put more resources or to build more infrastructures (like community clinics) and expect good results. The important question is whether the planners and policy makers have the time and the inclination to have a critical look at all these interdependent elements of the health system with a view to make their efforts part of an integrated comprehensive approach.

\subsection{Political Instability and Lack of Commitment}

As a developing country Bangladesh is faced with political instability and unrest that often turn into violence. Such political unrest (often coupled with street violence and destruction of public and private property) has significant adverse impact on the economy. Health system is the indirect victim of such political turmoil. During hartal (total shutdown of public and private transportation and of day-today economic activities) doctors and nurses (as well as others) are afraid to go to work due to lack of safety and security. Patients also face similar problems and can hardly seek needed health care services during such political disturbances. 
In other words, political instability and violence paralyses the health care system.

Moreover, political parties in Bangladesh seem to have little commitment to shun violence or to honor their preelection "promises". Every government has promised to ensure health for all and enshrined it in the constitution. Nevertheless, the promise remains unfulfilled even after forty years of the independence of Bangladesh On the other hand, intolerable corruption within and outside the health sector seems to have further deprived the country of its resources and denied it of decent human development. It is a country where the rich and powerful (including political big shots) routinely fly to Singapore, Thailand or India to avail health care services. There is hardly any commitment to improve the health system at home so that people at large could benefit. Clearly the health system requires a strong and efficient steward to come out of these drawbacks and deficits. It is unfortunate that the health system in Bangladesh does not seem to have an effective steward.

\subsection{Weak Health Information System}

Reliable and up-to-date health-related information is essential for developing an efficient health system. Thus WHO has emphasized on it as one of the building blocks of any health system (WHO, 2008). Only collecting raw data is not enough; those data must be managed, analyzed and disseminated systematically to the appropriate authority to facilitate decision-making and to take prompt actions. Over the years, many nation-wide as well as smaller scale surveys, surveillances and research studies have been conducted in the health sector of Bangladesh; but it still do not follow a standardized procedure to collect and manage health-related data from all health facilities at a regular interval. By following such unified and standardized health information system, Bangladesh can improve the efficiency of all other components of its health system.

\section{Discussion}

The challenges faced by the health system are multifarious and varied. Bangladesh has a severe shortage of physicians, nurses, midwives, and health technicians of various kinds. The deficit will keep on rising as the population increases. Inadequate number of appropriately trained human resources for health in Bangladesh is a strong limiting factor for population health [31]. In terms of health technicians of various kinds (from laboratory technicians to physiotherapists) the deficit is almost half a million. Midwives and community health workers are also in short supply. The gap between what the government has assessed (sanctioned) as requirement for providing healthcare services and the positions vacant clearly shows that Bangladesh has to make much greater efforts in ensuring accessibility to essential health care services. Moreover, the human health resources are heavily concentrated in urban centers, depriving rural areas of much needed human resources for health. According to Bangladesh Health Watch report (BNHA 2011) $62 \%$ of medical doctors in Bangladesh are working in the private sector. In addition, the health workforce is skewed towards doctors with a ratio of doctors to nurses of 1:0.4, and that of doctors to technologists of 1:0.24, in stark contrast to the WHO recommended ratio of 1:3.5.

Statistics on private sector appointment of medical staff are not available. However, the physicians in public sector often provide services in private hospitals. Moreover, Bangladesh has only 0.4 hospital bed per 1,000 population compared to that of 0.9 bed per 1,000 population in Ghana (WHO, 2011). Likewise, although at a similar economic level as Bangladesh, Kenya has 35 percent higher number of hospital beds per 1,000 populations.

Another problem plaguing the health system is the sorry state of infrastructural facilities. It should be noted that the government has a policy of establishing 1 Community Clinic for every 6,000 population covering rural Bangladesh. However, it is yet to be fully implemented.-In most cases, community clinics consist of two rooms with drinking water and lavatory facilities, and a covered waiting room. Unfortunately it remote areas of Bangladesh community clinics usually do not have even such meagre infrastructural facilities.

So far as human resources for health is concerned, it is not even clear if the sanctioned positions are sufficient to provide healthcare services to all citizens covering their needs. It is more important to look at the distribution of health care expenditure of Bangladesh. In Bangladesh, the major sources of healthcare funding include: households, government, NGOs and development partners. Insurance makes up a small share of the total source of health care financing in Bangladesh (BNHA 2003). The continued absence of social insurance and a minuscule private insurance market are compelling the house-holds, particularly the rural poor, to bear a large proportion of the national health expenditure through direct or out of pocket (OOP) payments. Household OOP expenditures constitute by far the largest component of the Total Health Expenditure (THE) - its share was around $69 \%$ in 2001 (BNHA 2003). The share of out-of-pocket expenditure in the total health expenditure increased from $57 \%$ in 1997 to $64 \%$ in 2007 .It should be noted here that while basic health care service is supposed to be free in public hospitals, patients end up bearing the costs of medicine and laboratory tests, as well as some additional unseen costs .Moreover, 5,122 registered diagnostic centres are currently operating in Bangladesh (along with many unregistered ones). Apart from these, there are a large number of private clinics and hospitals in different districts and cities that are not registered. Private for profit clinics/hospitals, geared toward maximizing profit, usually target middle- to high income segments of the society. According to Health Bulletin 2013 there are 2,983 registered private hospitals and clinics in the country with about 45,485 beds. Only a few among these have free beds for the poor. The health system information technology (IT) is primarily focused on family planning, safe motherhood, child health, and immunization. Unfortunately the health information system does not cover chronic non-communicable diseases 
(NCDs) - the fastest growing disease burden and threat to the health and wellbeing of the people of Bangladesh.

The existing inequity in the health system is too obvious to be ignored. The heavy burden of OOP makes it extremely difficult for the poor to access needed health care services. Needless to say, not only the poor but also some in the middle class citizens dread being afflicted with a serious health crisis.

\section{Conclusion}

In the light of the findings of this paper, it can be fairly argued that Bangladesh faces a lot of challenges in its health system. These challenges must be resolved in order to improve the existing health system, so that the disadvantaged and vulnerable people can get better access to basic health care services. Health is a fundamental human right, and regardless of their socio-economic status everybody has the right to enjoy optimal health status. The paper emphasizes once again the issue of equity in health systems, and the importance of a multisectoral comprehensive approache to improve the health system. The health system in Bangladesh desperately needs a dynamic leadership that is prepared to design and enforce evidence-based policies and programs. The steward of the health system must have a strategic vision and determination to improve and strengthen both the public and private health sectors of the country. Equity must be the overarching guiding principle underpinning the health system.

\section{References}

[1] International Relations and Security Network, Primary Resources in International Affairs (1972). Constitution of the People's Republic of Bangladesh.

[2] Coker, R.J., Atun, R.A. \& McKee, M. (2004). Health care system frailties and public health control of communicable disease on the European Union's new eastern border. The Lancet 2004; 363: 1389-92

[3] Barker, P.M., McCannon, C.J., Mehta, N., Green, C., Youngleson, M.S., Yarrow, J., Bennett, B. \& Berwick, D.M. (2007). Strategies for the Scale-up of Antiretroviral Therapy in South Africa through Health System Optimization. The journal of Infectious Diseases 2007; 196:S457-63

[4] Mahmood, S.A.I (2012). Health Systems in Bangladesh. The iMedPub Journal 2012; Vol 1, No. 1:1. Doi: 10.3823/1100.

[5] G., Lansung, M.A., Mitta, V., Bornemisza, O., Blakley, M., Kley, N., Burgess, C. \& Atun, R. (2010). Health systems strengthening: A common classification and framework for investment analysis. Health Policy and Planning 2010; 1-11. Doi: $10.1093 /$ heapol/czq053.

[6] Islam, A., Bangladesh health system in transition: selected articles. 2009: James P. Grant School of Public Health, BRAC University.

[7] Official website of The World Bank. Retrieved from 29 September 2014. http://www.worldbank.org/en/country/bangladesh
[8] World Bank. 2007. Improving living conditions for the urban poor. Bangladesh Development Series, paper no. 17. Dhaka

[9] Bangladesh Bureau of Statistics (BBS). 2011. Statistical pocketbook of Bangladesh 2010. Dhaka: BBS.

[10] The World Bank (2011). World Development Report 2011.

[11] Vaughan, J.P., E. Karim and K. Buse. 2000. Health care systems in transition III. Bangladesh, part I. An overview of the health care system in Bangladesh. Journal of Public Health22 (1): 5-9.

[12] Ullah, A.K.M.A. 2004. Bright city lights and slums of Dhaka city: Determinants of rural-urban migration in Bangladesh. Migration Letters 1 (1): 26-41

[13] Roy, G.S. and A.Q.M. Abduallah. 2005. Assesing needs and scopes of upgrading urban squatters in Bangladesh.BRAC University Journal 2 (1): 33-41

[14] Riley, L., A. Ko, A. Unger and M. Reis. 2007. Slum health: Diseases of neglected populations. BMC International Health and Human Rights 7 (2): 1-6

[15] Financial System Management Unit. 2011.Bangladesh economic review. Dhaka: Finance Division, Ministry of Finance.

[16] Engelgau. M.M., S. El-saharty, P. Kudesia, V. Rajan, S. Rosenhouse and K. Okamoto. 2011. Capitalizing on the demographic transition: tackling no communicable diseases in South Asia. Washington, DC: World Bank.

[17] Bleich, S.N., T.L.P. Koehlmoos, M. Rashid, D.H. Peters and G. Anderson. 2011. No communicable chronic disease in Bangladesh: Overview of existing programs and priorities going forward. Health policy 100 (2011): 282-289.

[18] World Bank. 2011b. Bangladesh-Health Sector Development Program. Dhaka.

[19] Bangladesh Bureau of Statistics (BBS). 2011. Statistical pocketbook of Bangladesh 2010.Dhaka: BBS.

[20] Trading Economics. 2012a. Bangladesh GDP Annual Growth Rate. http://www.tradingeconomics.com/bangladesh/gdpgrowth-annual (accessed 18 April 2012).

[21] World Bank. 2012d. World development report 2012: Gender equality and development. Washington, DC.

[22] World Bank. 2011. Bangladesh-Health Sector Development Program. Dhaka.

[23] Bangladesh Health Watch (BHW). 2011. Moving Towards Universal Health Coverage.

[24] Directorate General of Health Services (DGHS). 2010. Secondary and Tertiary Health Care Facilities in Bangladesh. Dhaka: DGHS.

[25] World Bank. 2012b. Death rate, crude (per 1,000 people), Bangladesh 2012. : World Bank. http://data.worldbank.org/indicator/SP.DYN.CDRT.IN (accessed 19 April 2012)

[26] Bangladesh Health Watch (BHW). 2007. Bangladesh State of Health Report: Health Workforce in Bangladesh, Who Constitutes the Healthcare System? James P grant School of Public health, BRAC University, Bangladesh. 
[27] Joint Learning Initiative (2004). Human Resources for Health: Strategies for Crisis and Sustainability.

[28] Bangladesh Health Watch (2012). Bangladesh Health Watch Report 2011: Moving towards Universal Health Coverage.

[29] WHO (2008). The World Health Report 2008: "Primary Health Care Now More than Ever".
[30] United Nations Children's Fund (UNICEF, 2011). UNICEF Annual Report 2010.

[31] slam, A. and T. Biswas, Health System Bottlenecks in Achieving Maternal and Child Health-Related Millennium Development Goals: Major Findings from District Level in Bangladesh. 